\title{
Missing Radiopaque Foreign Body in Plain X-ray
}

\author{
Muhammet Demir'1, Abdurrahman Emir¹, Kubilay Kınoğlu², Ali Tavaslı1', Habib Bostan³ \\ 'Department of Mortuary, Council of Forensic Medicine, İstanbul, Turkey \\ 2Department of Third Specialization Board, Council of Forensic Medicine, Istanbul, Turkey \\ ${ }^{3}$ Department of Second Specialization Board, Council of Forensic Medicine, İstanbul, Turkey
}

\section{ABSTRACT}

Introduction: The radiological investigations that will be performed after the hemodynamic stabilization of trauma cases presenting to the emergency room are of vital importance when deciding on the treatment to be administered to the patient. Posteroanterior chest radiography was not applied in the proper position, to include all the soft tissues of the chest and shoulder, after an injury caused by a sharp object in our case. Therefore, a radiopaque foreign object retained within the body was not detected.

Case Report: Our case was brought to the emergency room because of a stabbing injury, but no pathological findings were determined at the initial examination or based on the X-graphs taken. Approximately 1 year after discharge, the patient presented to another hospital because of a persistent swelling and pain in the left armpit. A metallic image consistent with a knife point 7-8 cm in length was determined to be under the left armpit.

Conclusion: The radiographs not taken in the proper position may lead to undesirable consequences. Therefore, we recommend that great attention should be paid while taking the radiographs, ensuring the proper position and careful evaluation.

Keywords: Diagnostic imaging, emergency medicine, malpractice, forensic medicine

Received: 08.04.2015 Accepted: 30.07.2015

\section{Introduction}

People may present to emergency departments for a variety of reasons, including injury, assault, sharp object injuries, and gunshots. Radiologic evaluations of these cases are important tools for emergency physicians (1). Based on the radiographs taken, evaluations are made concerning whether there are any pathological findings in the bone, soft tissues, and/or visceral organs. There are cases in the literature indicating that pathologies can sometimes be missed because the radiography was not performed at the proper position (2). However, as with our case, there is no case in the literature of a knife point retained within the body because of the failure to take a posteroanterior chest radiography at the proper position after a sharp object injury. In this report, we present the case of a patient who was evaluated by the Institution of Forensic Medicine regarding a claim of malpractice.

\section{Case Report}

A 19-year-old male patient presented to a hospital due to a sharp object injury. His wound was sutured and then he was referred to the emergency department of another hospital. When a physical examination was performed at the emergency department, a 1-2 cm sutured cut and subcutaneous hematoma were determined at the posterior axillar line of the left armpit. A posteroanterior chest radiograph was taken (Figure 1). No pathological finding was determined during the examination performed by the emergency physician and the orthopedist. Because no pathological finding was determined and his general condition was good, the patient was discharged. Because of a persistent tenderness and occurrence of edema in the lesion area of the left armpit after 1 month, the patient presented to the same physician again. The physician performed only a physical examination and stated that the findings were suggestive of clinical improvement. The patient was sent home again.

The patient presented to another hospital with complaints of swelling and pain in the left armpit 1 year later. A computerized tomography was taken, and the patient learned that the knife point was retained within the muscle tissue of the left armpit, where he had previously been stabbed (Figure 2). The patient was referred to the department of thoracic surgery for an operation. A metallic foreign body (knife point) along the left scapula with a length of 7-8 cm was found and removed dur-

Address for Correspondence:

Abdurrahman Emir, Department of Mortuary, Council of Forensic Medicine, İstanbul, Turkey

E-mail: abdurrahmanemir@gmail.com

(C) Copyright 2016 by Emergency Physicians Association of Turkey - Available online at www.jemcr.org 
ing surgery performed under general anesthesia. The patient had an uneventful postoperative course and was discharged. Then, the patient registered a case against the emergency physicians. All relevant files were sent to the Institution of Forensic Medicine. The $2^{\text {nd }}$ Specialty Board of the Institution of Forensic Medicine investigated the file, and it was emphasized not only that the radiograph should have been taken at the proper position but also that the evaluation should have been performed more carefully.

\section{Discussion}

Radiologic investigations performed in the case of injuries presenting to the emergency department after hemodynamic stabilization are of vital importance for deciding the treatment to be performed on a patient (1). As is the case in many instances of injury, the initial imaging method that will be performed in thoracic injuries is also a chest radiograph. The sensitivity of plain chest radiographs in the evaluation of visceral organs and vascular structures, revealing minimal trauma fractures in the bones and demonstrating the presence of transparent foreign objects such as glass, is low compared with other imaging methods $(3,4)$.

According to a patient's clinical situation, anteroposterior radiographs may be taken in the standing, sitting, and supine positions and are used in the emergency department. Generally, there is a need to take radiographs in different positions to assist emergency department personnel. However, radiographs can be taken in improper positions because of both crowded conditions in the emergency department and carelessness. Therefore, pathological findings that should be noted may be missed $(5,6)$.

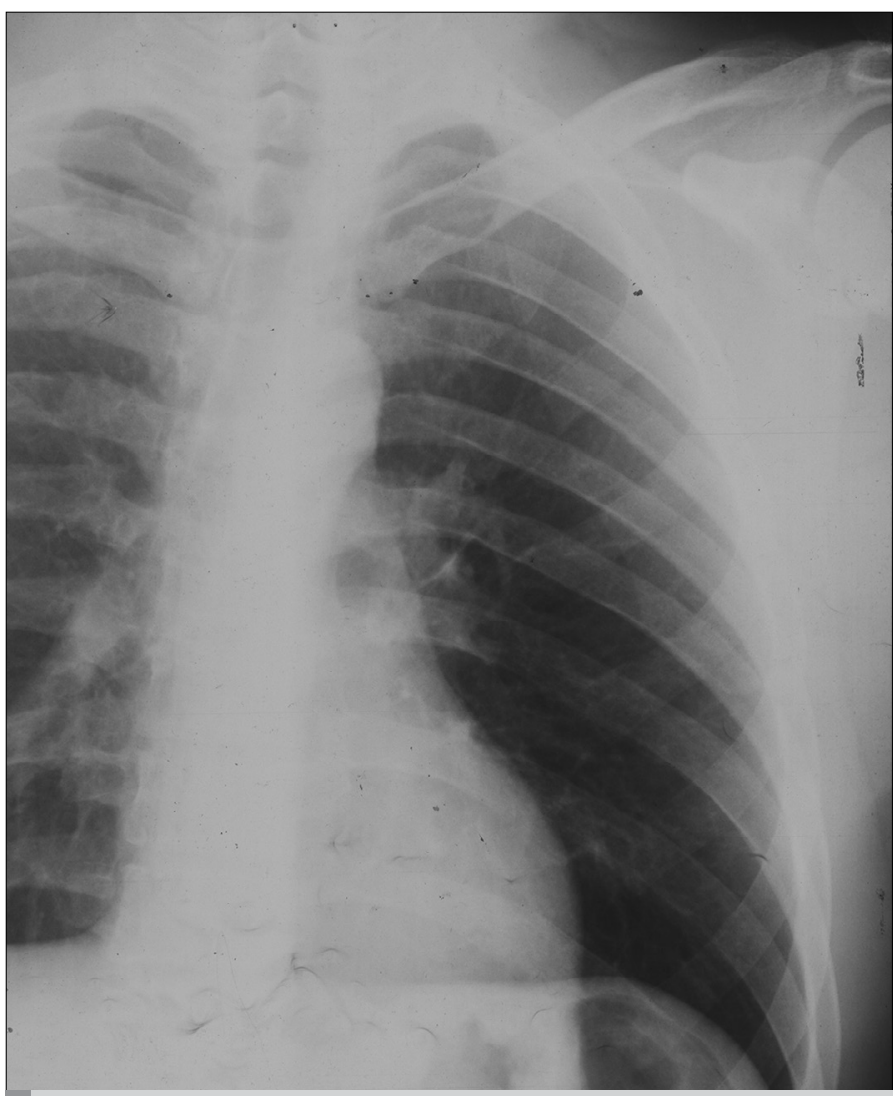

Figure 1. Posteroanterior chest radiograph
Our case's wound was sutured in the hospital where he was initially brought after a sharp object injury. After the suturing was complete, he was referred to the emergency department of another hospital. Subcutaneous edema was seen at inspection, and the palpation of a hard, foreign object during examination was suggestive of the presence of a foreign object, but it seems that the emergency physician did not perform a careful examination because the wound had been sutured earlier. No abnormality was determined when the examination was performed, and no pathology was detected from the radiographs taken in the emergency department.

The patient presented to another hospital with complaints of swelling and pain in the left armpit after 1 year. A metallic image consistent with a knife point was determined to be within the muscle tissue of his left armpit, based on the radiograph taken at this time. Although the foreign body forgotten in the body of our patient manifested symptoms in a very short time, the recognition of the foreign body took 1 year because of the carelessness of the physician performing the first examination. Sometimes, forgotten foreign bodies may cause symptoms only after months or even years (7). In our case, the knife point not detected in the armpit of the patient had features that could easily have been observed on the radiographs if they were taken in the proper position (i.e., a posteroanterior chest radiography that included all of the soft tissues of the chest and shoulder). However, the diagnosis was missed because the radiograph was not taken in the proper position.

The responsibilities of the emergency department physicians are as follows: to make a diagnosis as soon as possible after the patient presents to the emergency department, to perform all necessary laboratory and radiologic examinations, and to perform consultations for the selection of appropriate treatment or intervention methods. In the emergency health services field, the following conditions and cases increase the mission and responsibility of the physician compared with other cases: being obliged to initiate the treatment without taking a sufficient history or performing a careful imaging to detect the presence of forensic features in most cases. Legally, when a consulting physician is invited to see an emergent patient, he/she should evaluate the patient. If the opinion of the consult-

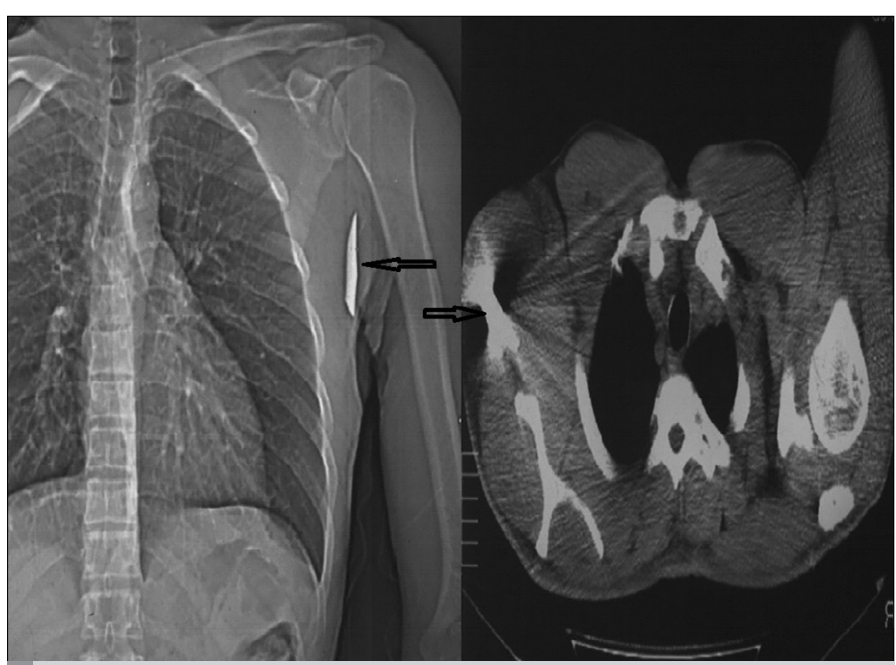

Figure 2. Computerized tomography 
ing physician is taken regarding the evaluation of the patient's health status, he/she is also responsible, as is the emergency physician, for the examination performed, the evaluation of the radiographs taken, and management of the patient's treatment. Therefore, both the emergency physician and the consulting physicians should have adequate scientific and technical information for the evaluation of the radiographs (8).

Foreign bodies may not be detected in the body because of various reasons such as the failure to take the radiographs in the proper position and not performing a careful wound exploration. These may result in negative social, psychological, and economic outcomes such as chronic health problems, exposure to infection, and reoperation on the patient (9). These cases may confront the physicians, and sometimes, other healthcare personnel with enforcements within the context of the criminal law and compensation law.

\section{Conclusion}

In recent years, the numbers of criminal or compensation actions brought against physicians has increased greatly. One of the important reasons for the increasing number of malpractice actions is that foreign bodies are not always determined in the body. Because of overcrowding and the need for rapid intervention in many emergency departments, the risk of encountering these types of cases is higher among emergency physicians. We recommend that trainings be arranged for the physicians regarding the evaluation of radiographs taken in emergency departments and that the overcrowding in emergency departments be reduced.

Informed Consent: This case was evaluated on the case file. So, written informed consent was not obtained from the patient who participated in this case.

Peer-review: Externally peer-reviewed.
Author Contributions: Concept - D.M., B.H.; Design - D.M., E.A., B.H.; Supervision - B.H., K.K.; Resource - T.A., E.A., D.M.; Materials - T.A., E.A., D.M.; Data Collection and/or Processing - K.K., E.A., D.M.; Analysis and/or Interpretation - D.M., E.A., K.K., B.H.; Literature Search - K.K., E.A., D.M.; Writing - D.M., E.A, K.K.; Critical Reviews D.M., E.A., B.H.

Conflict of Interest: The authors declared no conflict of interest.

Financial Disclosure: The authors declared that this study has received no financial support.

\section{References}

1. Lomoschitz FM, Eisenhuber E, Linnau KF, Peloschek P, Schoder M, Bankier AA. Imaging of chest trauma: radiological patterns of injury and diagnostic algorithms. Eur J Radiol 2003; 48: 61-70. [CrossRef]

2. Gandhi TK, Kachalia A, Thomas EJ, Puopolo AL, Yoon C, Brennan TA, et al. Missed and delayed diagnoses in the ambulatory setting: a study of closed malpractice claims. Ann Intern Med 2006; 145: 488-96. [CrossRef]

3. Esme H, Solak O, Yavuz Y, Yurumez Y, Degirmenci B, Terzi Y. Effects of thoracic injuries that can only be detected by computed tomography on treatment and morbidity. Turkish J Thorac Cardiovasc Surg 2006; 14: 222-6.

4. Trupka A, Waydhas C, Hallfeldt KK, Nast-Kolb D, Pfeifer KJ, Schweiberer L. Value of thoracic computed tomography in the first assessment of severely injured patients with blunt chest trauma: results of a prospective study. J Trauma 1997; 43: 405-11. [CrossRef]

5. Reisdorf $E$, Schwartz T. Introduction to emergency radiology. In Schwartz T. Reisdorf E, Editor. Emergency Radiology. 1 st ed. New York: McGraw Hill, 2000. p. 1-10.

6. Clinton J, Yaran M, Tsai S. Chest radiography in the emergency department. Ann Emerg Med 1986; 15: 254-6. [CrossRef]

7. Bostan H, Karakaya MA, Demir M, Cagdir AS, Hanci V. A case of surgical instrument left in the abdomen and taken out of the transverse colon. Hippokratia 2014; 18: 77-9.

8. Tugcu H, Yorulmaz C, Ceylan S, Baykal B, Celasun B, Koc S. The Knowledge And Ideas of the Physicians Who Participate in Emergency Services About Physician Responsibility in Emergency Cases and Forensic Medicine Problems. Gulhane Med J 2003; 45: 175-9.

9. Kurtulus A, Acar K, Boz B. Legal responsibility of the physician. Journal of Academic Design 2008; 2: 10-4. 